\title{
Special Issue: Advances in Combustion Research
}

\author{
Mohy S. Mansour ${ }^{1} \cdot$ Nevin Selçuk $^{2} \cdot$ Federico Beretta ${ }^{3} \cdot$ Andrea D'Anna $^{4}$ \\ Published online: 26 March 2021 \\ (C) The Author(s), under exclusive licence to Springer Nature B.V. 2021
}

This Special Issue contains 20 papers selected from a total of 195 papers presented at the Eleventh Mediterranean Combustion Symposium (MCS11), jointly co-sponsored by the Combustion Institute and the International Centre for Heat and Mass Transfer, and held in Costa Adeje, Tenerife, Spain, from 16 to 20 June, 2019. The aim of the Symposium was to give combustion scientists, engineers and students based predominantly in Mediterranean countries an opportunity to get together with colleagues from other global regions, to discuss and disseminate state-of-the-art research and recent advances in the field of combustion, and to enhance future collaborative research activities between scientists from different countries in the region. This Special Issue is the fifth in the series, started with the Seventh Mediterranean Combustion Symposium.

Following a preliminary selection by the editors of a subset of Symposium papers, with quality and fit to Journal scope being the principal criteria, the papers were then subjected to a rigorous peer-review process by three expert reviewers, as applied to any standard submissions to the Journal. This process was therefore independent from the review of the original conference submissions.

The Guest Editors are grateful for the opportunity to publish this Special Issue, and they hope that it will be regarded as a valuable contribution to the field of turbulent combustion of gaseous and liquid fuels.

Mohy S. Mansour

mansourm@aucegypt.edu

Nevin Selçuk

selcuk@metu.edu.tr

Federico Beretta

beretta@irc.cnr.it

Andrea D'Anna

andrea.danna@unina.it

1 Department of Mechanical Power Engineering, Cairo University, Cairo, Egypt

2 Department of Chemical Engineering, Middle East Technical University, Ankara, Turkey

3 Istituto Di Ricerche Sulla Combustione, Consiglio Nazionale Delle Ricerche, Napoli, Italy

4 Department of Chemical, Material and Industrial Production Engineering, University Federico II, Naples, Italy 
Publisher's Note Springer Nature remains neutral with regard to jurisdictional claims in published maps and institutional affiliations. 